\title{
Influence of environmental factors on retention of extensive green roofs with different substrate composition
}

\author{
Anna Baryła ${ }^{1, *}$, Agnieszka Karczmarczyk $^{1}$, Agnieszka Bus $^{1}$, and Edyta Hewelke $^{2}$ \\ ${ }^{1}$ Faculty of Civil and Environmental Engineering, Department of Environmental Improvement, Warsaw University of Life Sciences - \\ SGGW, Nowoursynowska 166, 02-787 Warszawa \\ ${ }^{2}$ Laboratory Water Center, Warsaw University of Life Sciences - SGGW, Nowoursynowska 166, 02-787 Warszawa
}

\begin{abstract}
Increasing recognition is being given to the adaption of green roofs in urban areas to enhance the local ecosystem. Green roofs may bring several benefits to urban areas including flood mitigation Analysis of environmental factors affecting the outflow of green roofs is the subject of many studies. The work assessed how environmental factors moisture of structural layers and antecedent dry weather period influence the retention on two types of green roof substrates. The monitoring of environmental factors and amount of runoff was carried out on two models of green roofs covered by extensive vegetation (mosssedum-herbs) with substrates of an organic-mineral and mineral composition for 8 months. A statistical regression approach identified potential antecedent meteorological factors and moisture indicators of extensive green-roof retention. Continuous field monitoring data revealed the combined effects of rainfall depth and antecedent dry weather period to explain the measured stormwater retention under a moderate climate conditions regime. It is important to incorporate site-specific planning and assessment prior to green infrastructure design.
\end{abstract}

\section{Introduction}

Green roofs in particular, have gained considerable attention in recent years as a potential cost-effective way to mitigate urban flood risk [1-5]. They are defined as roofs which are partially or completely covered with a growing medium (substrate) and vegetation (excluding pot vegetation) [5-9]. Whilst most SUDS (Sustainable drainage systems) require large spaces, green roofs require no additional space beyond a buildings footprint $[1,5,10]$. Furthermore, green roofs can be retrofitted onto existing buildings as well as incorporated into new developments [11]. This is particularly beneficial in urban areas where roofs can account for a high proportion of the total impervious land area [5, 12-13]. In addition to hydrological advantages, green roofs can also extend the longevity of a roof, improve the quality of air $[5,14]$, decrease the effects of urban heat islands, alleviate climate changes by the sequestration of carbon dioxide, add aesthetic values to urban architecture and increase biological diversity [15-17]. Green roofs ought to be viewed as ensuring a multifaceted input to a sustainable urban environment [18-20]. The water retaining capacity of green roofs depend on roof characteristics and local weather conditions [21]. Characteristics include thickness of the growing media, soil type, vegetation type, vegetation cover, roof age and slope. Weather conditions include intensity and duration of precipitation events, length of dry periods and air temperature [4]. Key hydrological mechanisms of green roofs include the interception of rainfall by the plant layer, infiltration and storage in the substrate and drainage layers, while additional moisture either forms runoff, or evapotranspires $[1,5,11]$. In many studies, it was shown that in the summer months, under high levels of evapotranspiration, the retention of such roofs is higher than during cooler months [22-24]. Studies carried out by [25] in Portland showed that the average water retention in green roofs in the winter period was $12 \%$, and in the summer period $-42 \%$. Similar results were obtained by [26], where the efficiency of green roofs was higher in the spring and summer months, and lower in those of winter and fall. According to [27], one of the potential means of improving retention in the winter would be the selection of vegetation accounting for species which carry out life processes in cool periods of the year, or ones which have the ability to store water. In addition to the time of the year, a parameter influencing the retention ability of green roofs is the amount and duration of the rainfall. [28], carrying out studies on an extensive roof, observed that water retention decreased from $90 \%$ for a rainfall depth of 13 $\mathrm{mm}$ to $39 \%$ with rainfall of $54 \mathrm{~mm}$. Another parameter that can influence the amount of retention on green roofs is the antecedent dry weather period (ADWP), or antecedent dry days, which is the duration of dry period prior to a precipitation event [7]. It can be stated that, if the ADWP is relatively long between rainfall events, the

\footnotetext{
*Corresponding author: anna_baryla@sggw.pl
} 
substrate has time to dry, which leads to an increase in the retention ability [29]. On the contrary, if ADWP is short, the substrate will have a shorter time to dry between subsequent rainfall events, leading to lower retention abilities $[4,30]$. The characteristics of ADWP have an influence on the seasonal differences in the retention of green roofs, which is caused by evapotranspiration [31-33]. Higher evapotranspiration in warmer periods of the year causes the faster drying and an increase in retention as opposed to cooler seasons [1, 7, 19]. As had been shown and mentioned earlier in numerous publications from various regions of the world, many factors can have an influence on the hydrology of green roofs $[8,18,34]$. In this paper studies on the influence of environmental factors such as rainfall depth, change in the moisture of structural layers (AVMC) and antecedent dry weather period (ADWP) on retention on green roofs of the extensive type were carried out.

\section{Materials and methods}

The studies were carried out on 2 models of green roofs of the extensive type, with various compositions of the substrate layer (Table 1). Models were located at the Water Centre of SGGW in the southern part of Warsaw. Analyzed data were collected in period of 1.08-30.09. 2016 and 01.04-30.09.2017.

Table 1. Characteristics of test models.

\begin{tabular}{|c|c|c|}
\hline Desig & GR 1 & GR 2 \\
\hline $\begin{array}{l}\text { Extensive } \\
\text { vegetation }\end{array}$ & \multicolumn{2}{|c|}{$\begin{array}{l}\text { Pre-cultivated vegetation mat XF317 } \\
\text { moss-sedum-herbs; thickness of } 2.5 \mathrm{~cm} \\
\text { (Sedum album, Sedum acre, Sedum } \\
\text { kamtschaticum, Sedum spurium, Sedum } \\
\text { reflexum, Sedum sexangulare, Dianthus } \\
\text { deltoides, Dianthus carthusianorum, and } \\
\text { Thymus vulgaris) (Xero Flor 2016). }\end{array}$} \\
\hline $\begin{array}{l}\text { Vegetation } \\
\text { layer-an } \\
\text { extensive } \\
\text { substrate with a } \\
\text { thickness of } 15 \\
\mathrm{~cm} .\end{array}$ & $\begin{array}{l}\text { SPG E-E - mixture of } \\
\text { washed sand, gravel, } \\
\text { limestone, crushed red } \\
\text { brick, broken fine } \\
\text { lime, peat and } \\
\text { compost; }\end{array}$ & $\begin{array}{l}\text { SPG E-M - type } \\
1 \text { mixture of } \\
\text { washed sand, } \\
\text { gravel, } \\
\text { limestone, } \\
\text { crushed red } \\
\text { brick; }\end{array}$ \\
\hline Filte & \multicolumn{2}{|c|}{$\begin{array}{l}\text { Polyfelt TS } 20 \text { polypropylene geotextile } \\
\text { with a GRK } 2 \text { strength class, weight } 125 \\
\mathrm{~g} / \mathrm{m}^{2} \text {; }\end{array}$} \\
\hline Drair & \multicolumn{2}{|c|}{$\begin{array}{l}\text { Terrafond Garden drainage mat 20L, } \\
\text { height } 2 \mathrm{~cm} \text {; }\end{array}$} \\
\hline Protec & \multicolumn{2}{|c|}{$\begin{array}{l}\text { Polyfelt TS } 20 \text { polypropylene geotextile } \\
\text { with a GRK } 2 \text { strength class, weight } 110 \\
\mathrm{~g} / \mathrm{m}^{2} \text {; }\end{array}$} \\
\hline Water & \multicolumn{2}{|c|}{$\begin{array}{l}\text { Heat-sealable bitumen sheeting root } \\
\text { resistant in accordance with PN-EN ISO } \\
\text { 13948; }\end{array}$} \\
\hline$\overline{\text { Und }}$ & \multicolumn{2}{|c|}{$\begin{array}{l}\text { OSB boards with thickness } 16 \mathrm{~mm} \text { with } \\
\text { slots not exceeding } 5 \mathrm{~mm} \text {. }\end{array}$} \\
\hline
\end{tabular}

Models of green roofs of the extensive type were prepared in two trays, with the dimensions of $1.0 \times 2.0 \mathrm{~m}$ and a with a slope of $2 \%$ in relation to the land surface (Figure 1). Two types of substrates, which were prepared in accordance with [35] guidelines were applied in the constructions of green roofs. In the first model, GR1 mineral-organic substrate, i.e. a mixture of washed sand, gravel, limestone, crushed red brick, broken fine lime, peat and compost was used, while the second model made of GR2 mineral substrate - mixture of washed sand, gravel, limestone and crushed red brick (Table1).

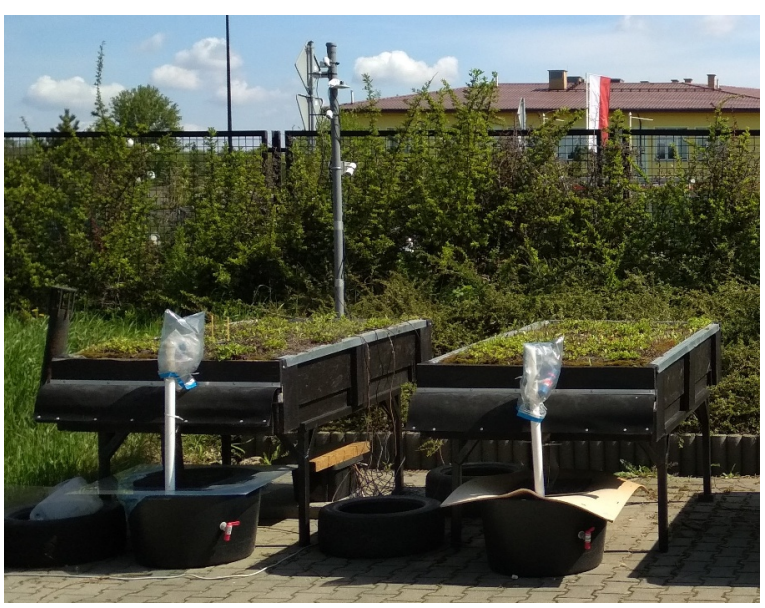

Fig. 1 Experimental object.

The physical properties of selected materials were determined in accordance with the following standards: particle size distribution PN-ISO 11277:2005 (Figure 3). Then, the $\mathrm{pF}$ curve was determined by the silt block method $\left(\mathrm{pF}_{0}-\mathrm{pF}_{2.7}\right)$ and the pressure chamber method $\left(\mathrm{pF}_{3.0}-\mathrm{pF}_{4.2}\right)$ (Figure $\left.2 \mathrm{a}, \mathrm{b}\right)$.

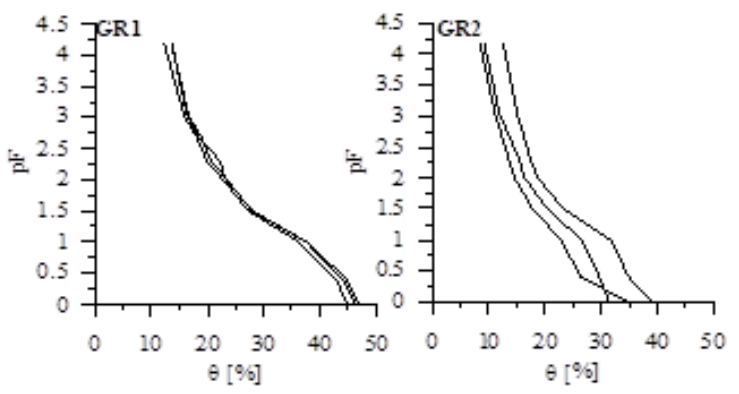

Fig. 2 Water retention curves in substrate layer for GR1 and GR2 (a, b).

It was assumed, that the value of $\mathrm{pF}_{0}$ represents the maximum water capacity $(\mathrm{MWC})$, and $\mathrm{pF}_{2.0}$ represents the field capacity (FC), while the value of $\mathrm{pF}_{2.9}$ became the lower allowable limit of water content, related to water storage in a drought period, and finally the $\mathrm{pF}_{4.2}$ is the wilting point (WP). The effective retention (ER) range was assumed between $\mathrm{pF} 1.8$ and 3.7 (when 3.7 stands for moisture when plant growth terminates), and potential retention (PR) - between $\mathrm{pF} 1.8-4.2$. The effective retention (ER) was $11 \%$ for the GR1 model and $6 \%$ for the GR2 model, whereas potential retention (PR) was $14 \%$ for GR1 and $8 \%$ for GR2. On the basis of values of water available to plants $\left(\mathrm{pF}_{2.0}-\mathrm{pF}_{4.2}\right)$ as well as a given thickness of the substrate equal to $15 \mathrm{~cm}$, the maximum water volume which can be retained by this 
layer was recalculated for $1 \mathrm{~m}^{2}$ [36]. For the GR1 substrate it amounted to $15.03 \mathrm{dm}^{3}$, whereas for GR2 $9.80 \mathrm{dm}^{3}$. Based on a conventional approach relying on determining atmospheric precipitation suggested and assumed in other studies of the "green roof" type, rainfall events separated by six or more hours are classified as independent events [1, 32, 34, 37-38]. There were, however, situations when runoff from a previous event was still ongoing and another event occurred. In such situations, the two adjacent "events" were combined into one.

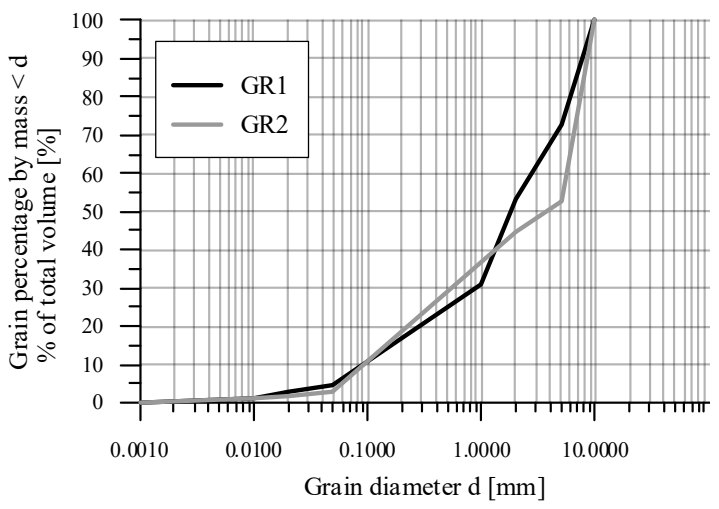

Fig. 3 Substrate granulation curves.

For consistency with previous green roof performance analysis, individual events were defined as being separated by continuous dry periods of at least six hours - Antecedent Dry Weather Period, (ADWP $>6 \mathrm{~h})$. For each event, the retention of the green roof $(\mathrm{R} \%)$ was determined. Based on the measurements, a relative daily retention for each container was calculated using Equation 1 [40]:

$$
R=\frac{P-H}{P} \cdot 100 \%
$$

where: R-retention [\%], P - precipitation $[\mathrm{mm}]$ and $\mathrm{H}$ runoff $[\mathrm{mm}]$.

Runoff measurements were taken after each rainfall event by volume. Starting in 2016, runoff was measured using recorders manufactured by Odyssey. The measurement dishes were calibrated at the Water Centre of SGGW in Warsaw. Changes in moisture content were measured using TDR (Time Domain Reflectometry) sensors [40-41] in a substrate $80 \mathrm{~mm}$. The data s were registered using a data recorder in both models starting from August 2016 at 10-minute time intervals. In the next stage, it was assumed that the last reading of moisture content prior to beginning each event will be the preceding antecedent volumetric moisture content (AVMC). The obtained results were used to identify significant environmental factors which may play an important role in maintaining the retention of rainwater on a green roof in a moderate climate. Multiple linear regressions (MLR) was used for statistical analysis. Three types of parameters were tested as explanatory variables for rainwater retention on green roofs, i.e.: rainfall depth antecedent dry weather period and antecedent volumetric moisture content.. Normality was assessed using the Shapiro-Wilk test. Following initial analyses, the exploratory multiple linear regression was carried out in order to assess the explanatory power between potential factors and the percentage retention using a regression method. The dependent variable $\mathrm{R}$ (\%) was transformed in a logarithm in all analyses in order to optimize the linearity and equality of variation unless otherwise specified. Next, multiple regression methods were applied in order to identify factors with the highest explanatory power. All statistical analyses were carried out using STATGRAPHICS Centurion XVI software.

\section{Results}

\subsection{Weather profile of the study period}

During the studies carried out, 116 days of rainfall were noted, with total rainfall of $645.10 \mathrm{~mm}$ (average 5.61 $\mathrm{mm}$; max. $54.10 \mathrm{~mm}$; min. $0.1 \mathrm{~mm}$; median $2.80 \mathrm{~mm}$ ). Rainfalls with $\mathrm{P}<5 \mathrm{~mm}$ comprised $63.8 \%$ of all noted rainfalls, rainfalls with a $5-10 \mathrm{~mm}$ comprised $21.6 \%$, those of $10-20 \mathrm{~mm}-9.5 \%$, rainfalls with $20-30 \mathrm{~mm}-$ $1.7 \%$, while those of $30 \mathrm{~mm}-3.4 \%$ (Figure 4 ).

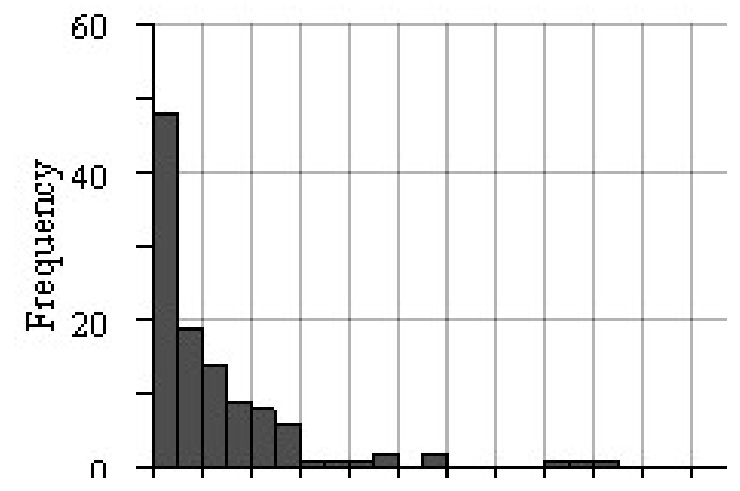

Fig. 4 Distribution of rainfall depths during the observation period.

\subsection{Relationship between rainfall and retention ability}

Table 2. Spearman's rank correlation coefficients $r$ and probability $p$ (in brackets) of $\ln (\mathrm{DR} 1)$ and P-rainfall depth [mm], ADWP [h], AVMC [\%].

\begin{tabular}{|l|c|c|c|c|}
\hline & $\begin{array}{c}\text { ADWP } \\
{[\mathbf{h}]}\end{array}$ & $\begin{array}{c}\mathbf{L n}(\mathbf{D R} 1) \\
{[\%]}\end{array}$ & $\begin{array}{c}\text { AVMC } \\
{[\%]}\end{array}$ & $\begin{array}{c}\mathbf{P}_{\text {dep. }} \\
{[\mathbf{m m}]}\end{array}$ \\
\hline ADWP [h] & & 0.2069 & -0.4188 & -0.0539 \\
& & $\mathbf{( 0 . 0 2 5 8 )}$ & $\mathbf{( 0 . 0 0 0 0 )}$ & $(0.5656)$ \\
\hline Ln(DR1) [\%] & & & -0.2637 & -0.5437 \\
& & & $(0.0042)$ & $\mathbf{( 0 . 0 0 0 0 )}$ \\
\hline AVMC [\%] & & & & -0.0346 \\
& & & & $(0.7123)$ \\
\hline
\end{tabular}

The linear relationship between rainfall depth and the retention, for both the GR1 as well as GR2 model, showed a negative correlation for of $\mathrm{r}(116)=-0.54$, $\mathrm{p}<0.05$, and $\mathrm{r}(116)=-0.57$. The obtained negative values 
of correlation showed that, along with an increase in depth, the retention ability of green roofs decreases (Table 2, Table 3).

Table 3. Spearman's rank correlation coefficients $r$ and probability $\mathrm{p}$ (in brackets) of $\ln (\mathrm{DR} 2)$ and P-rainfall depth [mm], ADWP [h], AVMC [\%].

\begin{tabular}{|l|c|c|c|c|}
\hline & $\begin{array}{c}\text { ADWP } \\
{[\mathbf{h}]}\end{array}$ & $\begin{array}{c}\text { Ln(DR2) } \\
{[\%]}\end{array}$ & $\begin{array}{c}\text { AVMC } \\
{[\%]}\end{array}$ & $\begin{array}{c}\mathbf{P}_{\text {dep. }} \\
{[\mathbf{m m}]}\end{array}$ \\
\hline ADWP [h] & & 0.2082 & -0.2544 & -0.0539 \\
& & $\mathbf{( 0 . 0 2 4 9 )}$ & $\mathbf{( 0 . 0 0 5 9 )}$ & $(0.5656)$ \\
\hline Ln (DR2) [\%] & & & -0.1669 & -0.5746 \\
& & & $(0.0733)$ & $\mathbf{( 0 . 0 0 0 0 )}$ \\
\hline AVMC [\%] & & & & 0.0003 \\
& & & & $(0.9971)$ \\
\hline
\end{tabular}

\subsection{Relations between ADWP, AVMC and retention}

According to [43], two parameters, i.e. ADWP and AVMC, determine the preceding level of moisture in the substrate, and a relationship should exist between these two indicators (ADWP and AVMC are determinants of substrate's antecedent moisture level, an association should exist between these two indicators). Negative relationships between AVMC and ADWP were determined for both analysed roofs, both with a mineralorganic as well as organic substrate. The $\mathrm{r}(116)=-0.42$ was obtained for the roof with the mineral-organic substrate, and $p<0.05$ (Table 2, Table 3). This suggests that, along with an increase in the length of a dry period, AVMC is lower. When it comes to the relationship between these two parameters and the retention of a green roof, ADWP for both roofs was $\mathrm{r}(116)=0.21$, $\mathrm{p}<0.05$, while AVMC for roof GR1 was $\mathrm{r}(116)=-0.26$, $\mathrm{p}>0.05$ for the roof with the mineral-organic substrate. MLR was carried out to compare the influence of the two mentioned determinants of soil moisture content (AVMC and ADWP) as well as rainfall depth in order to describe retention. ADWP and rainfall depth significantly explained rainwater retention, $\mathrm{F}(2,114)=$ $27.48 \mathrm{p}<0.05$, with both variables significantly influencing the model (Table 4 ). The corrected $\mathrm{R}^{2}$ was 0.33 , which suggests that this model is responsible for $33 \%$ variation of retention. In the case of the GR2 roof, the results were similar to GR1, F(2, 114) $=32.00$ $\mathrm{p}<0.05$, with the two variables significantly influencing the model. The corrected $\mathrm{R}^{2}$ was 0.36 , which suggests that the model is responsible for approximately $36 \%$ variation in retention. AVMC and rainfall depth explained rainwater retention, $\mathrm{F}(2,114)=33.97$, $\mathrm{p}<0.05$, while both variables contributed to the model to a greater extent than ADWP. The corrected $\mathrm{R}^{2}$ was 0.36 , which suggests that this model is responsible for $36 \%$ variation of retention. In the GR1 of the model with the mineralorganic substrate, similar relationships between AVMC and rainfall depth as parameters explaining the retention of rainwater on green roofs were obtained, $F(2,114)=$ $34.33, \mathrm{p}<0.05$, with both variables, with both variables significantly contributing to the model. The corrected $\mathrm{R}^{2}$ amounted to 0.37 , which suggests that the model is responsible for approx. $37 \%$ variation in retention.

Table 4. Equation Multiple linear regression.

\begin{tabular}{|l|l|l|}
\hline Eq. & \multicolumn{1}{|c|}{ Equation } & $\mathbf{R}^{\mathbf{2}}$ \\
\hline 1 & $\ln (\mathrm{R} 1)=4.381+(-0.04)\left(\mathrm{P}_{\mathrm{dep}}\right)+(0.002)(\mathrm{ADWP})$ & 0.33 \\
\hline 2 & $\ln (\mathrm{R} 2)=4.331+(-0,047)\left(\mathrm{P}_{\mathrm{dep}}\right)+(0.003)(\mathrm{ADWP})$ & 0.36 \\
\hline 3 & $\ln (\mathrm{R} 1)=5.07+(-0.04)\left(\mathrm{P}_{\mathrm{dep}}\right)+(-0.03)(\mathrm{AVMC})$ & 0.36 \\
\hline 4 & $\begin{array}{l}\ln (\mathrm{R} 2)=5.00+(-0.05)\left(\mathrm{P}_{\mathrm{dep}}\right)+(-0.05)(\mathrm{AVMC}) \\
5\end{array}$ & $\begin{array}{l}\ln (\mathrm{R} 1)=4.967+0.0009(\mathrm{ADWP})-0.039\left(\mathrm{P}_{\mathrm{dep}}\right)- \\
0.027(\mathrm{AVMC})\end{array}$ \\
\hline 6 & $\begin{array}{l}\ln (\mathrm{R} 2)=4.815+0.0009(\mathrm{ADWP})-0.038\left(\mathrm{P}_{\mathrm{dep}}\right)- \\
0.042(\mathrm{AVMC})\end{array}$ & 0.39 \\
\hline
\end{tabular}

\section{Significant factors of retention}

A series of environmental factors were analysed in the article. Multiple linear regression (MLR) showed that the combination of rainfall depth, ADWP and AVMC explains the retention of rainwater, $\mathrm{F}(3,113)=22.85$, $\mathrm{p}$ $<0.05$, while only rainfall depth and AVMC has a significant contribution to retention $(\mathrm{p}<0.05)$. The corrected $\mathrm{R}^{2}$ was 0.38 , which suggests that this model is responsible for approximately $38 \%$ variation in retention (Table 4, eq. 5). For the GR2 model, the corrected $\mathrm{R}^{2}$ amounted to 0.39 and (Table 4, eq. 6). As one would expect, the regression coefficients indicate that as rainfall depth increases, retention capacity decreases. Longer ADWP leads to higher retention capacity. Modeled retention was calculated using eq. 5 and 6 (Table 4) which includes measured rainfall depth, ADWP, AVMC values of each event. Scatter plot of measured versus modeled retention revealed a close relationship (Figure 5).

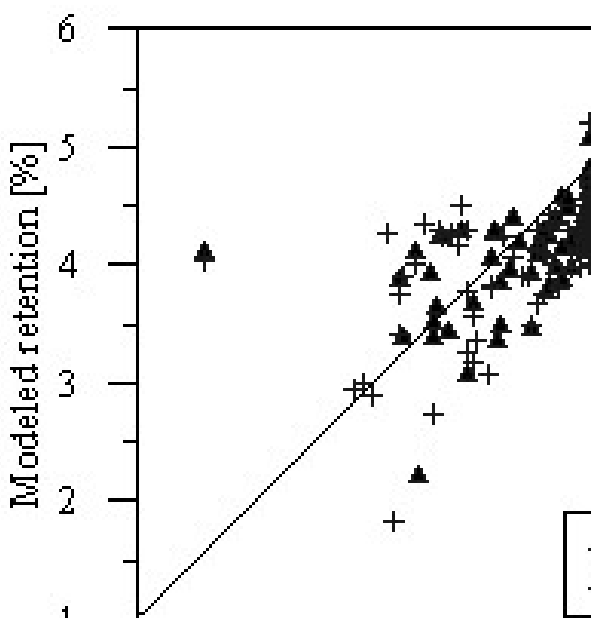

Fig. 5. Scatter plot of measured vs. modeled retention using Eq. 5 and 6 . The solid linis the 1:1 line. 


\section{Conclusions}

In the article, the role of key environmental factors on rainwater retention on green roofs under the conditions of a continental wet climate was assessed. Both correlation and multiple linear regression analyses indicate that rainfall depth relates strongly to percent retention. These findings concur with prior studies that the total rainfall depth can exert strong influence on retention $[11,27,43]$. The retention capacity of green roofs is inherently finite and so the retention percentage to a great extent is dependent upon rainfall input. When the rainfall input is close to filling the system's total storage capacity at a given time and under specific internal conditions, the contribution of other factors may be significant [43]. But when the disparity between the two is substantial, the effect of rainfall depth on retention would outweigh other factors. Thus, for the purpose of mitigating large rainfall events, green roof's detention and peak flow reduction potentials should not be over looked Green roof system's moisture retention capacity can be subjected to local weather patterns prior to a rainfall event [43]. The capacity for water retention influences green roofs' stormwater mitigation potential. ADWP has been utilized by various green roof stormwater studies as a proxy to antecedent moisture condition. It is thought that a longer dry period prior to a precipitation event would yield greater retention [4, 30]. The volumetric water content of the growing substrate, or AVMC, can serve as a more direct and reliable alternative proxy to antecedent moisture condition [7, 29]. AVMC data can be acquired with commonly available TDR volumetric soil moisture sensors [43]. Substrates with low AVMC would yield greater retention. This study has found that the relationship between AVMC and ADWP were moderately negative. Regardless of the varying degrees of initial moisture level (after intense rainfall or light rainfall), the substrate's antecedent volumetric water content of each event was still moderately associated with the duration of the dry period. Correlation analysis also revealed that, individually, AVMC had a moderately negative association with retention; whereas ADWP did not exhibit any statistically significant correlation with retention. In both models, similar relationships were obtained when it comes to the influence of environmental factors on the retention of rainwater. Both models of green roofs of the extensive type were found to have a similar construction, though the model with the addition of low moor peat and compost revealed higher moisture content.

\section{Acknowledgements}

Publication supported by the Polish Ministry of Science and Higher Education as a part of the program of activities disseminating science from the project „Organization of the First International Science Conference - Ecological and Environmental Engineering”, 26-29 June 2018, Kraków.
The publication and research was conducted in the frame of cooperation project: "Testing of extensive green roof runoff for volume quantity and phosphate concentration" (1/KKŚ/2016).

\section{References}

1. Stovin V., Poë S., Berretta C. Journal of Environmental Management, 131, 206-215. (2013).

2. Beck D.A. et al. Environmental Pollution. 159, pp. 2111-2118. (2011).

3. Barszcz M. Pol. J. Environ. Stud. vol. 25, No. 4, 1403-1413.(2016).

4. Pęczkowski G., Kowalczyk T., Szawernoga K., Orzepowski W., Żmuda R., Pokładek R. Water. 10, 1185. (2018).

5. Nawaz R., McDonald A., Postoyko S. Ecological Engineering. 82, 66-80. (2015).

6. Mickovski S.B. et al. Ecological Engineering. 61P, pp.706-714. (2013).

7. Berndtsson J.C. Ecological Engineering. 36, pp. 351-360. (2010).

8. Olly L.M. et al. Urban Forestry \& Urban Greening. 10, pp.311-316. (2011)

9. Karczmarczyk A., Baryła A., Kożuchowski P. Sustainability 9(10), 1795. (2017).

10. Zhang S. \& Guo Y. Journal of Hydrologic Engineering. 18, pp.19-28. (2013).

11. Stovin V., Vesuviano G., Kasmin H. Journal of Hydrology, 414-415, 148-161. (2012).

12. Castleton H.F. et al. Energy and Buildings. 42, pp.1582-1591. (2010).

13. Carson T.B. et al. Environmental Research Letters. 8, pp.1-13. (2013).

14. VanWoert N. D., Rowe D. B., Andresen J. A., Rugh C. L., Fernandez R. T., Xiao L. Journal of Environmental Quality, 34, 1036-1044. (2005).

15. Banting D., Doshi H., Li J. Missios P. Report on the Benefits and Costs of Green Roof Technology for the City of Toronto. Available online: https://web.toronto.ca/wpcontent/uploads/2017/08/8 f39-Report-on-the-Environmental-Benefits-andCosts-of-Green-Roof-Technology-for-the-City-ofToronto-Full-Report.pdf (accessed on 10 October 2017). (2017).

16. Köhler M. Urban Habitats. 4: 3-26. (2006).

17. Catalano C., Laudicina V., Badalucco L., Guarino R. Ecological Engineering. vol. 115, p. 15-26. (2018).

18. Dunnet N., Kingsbury, N. Planting green roofs and living walls. Portland, Oregon: Timber Press. 254 (2004).

19. Szota C., Farrell C., Williams N., Arndt S., Fletcher T. Science of the Total Environment 603-604, p. 340-351. (2017). 
20. Pawlat-Zawrzykraj A., Podawca K. Acta Scientiarum Polonorum-Formatio circumiectus. vol. 16, 4, p. 65-83. (2017).

21. Baryła A., Karczmarczyk A., Brandyk A., Bus A. Wat. Sci. Tech. 77 (12), 2886-2895. (2018).

22. Mentens J., Raes D., Hermy M. Landscape and Urban Planning, 77, 217-226. (2006).

23. Carson T.B.; Marasco D.E.; Culligan P.J.; McGillis W.R. Environ. Res. Lett. 8. (2013).

24. Baryła, A., Karczmarczyk, A., Bus, A. J. Ecol. Eng. 19(5):86-92. (2018).

25. Spolek G. Urban Ecosyst. 11, p. 349-359. (2008).

26. MacMillan G. York University Rooftop Garden Stormwater Quantity and Quality Performance Monitoring Report. In Proceedings of Greening Rooftops for Sustainable Communities, Portland, OR, USA, 2-4 June 2004.

27. Schroll E., Lambrinos J., Righetti T., Sandrock D. Ecological Engineering, 37, 595-600. (2011).

28. Carter T.L. and Rasmussen T.C. Water Resources Association 42 (5), 1261-1274. (2006).

29. Fassman-Beck E., Voyde E., Simcock R., Hong Y. S. Journal of Hydrology. 490, pp.11-20. (2013).

30. Hathaway A.M. Hunt W. F., Jennings G. D. American Society of Agricultural and Biological Engineers. 51(1), pp.37- 44. (2008).

31. Van Seters T., Rocha L., Smith D., MacMillan G. Water Qual. Res. J. Can., 44(1), 33-47. (2009).

32. Palla A., Sansalone J.J., Gnecco I., Lanza L.G. Water Sci. Technol. 64, 766-773. (2011).

33. Graceson A., Hare M., Monaghan J., Hall N.
Ecological Engineering, 61, 328-334. (2013).

34. Mentens J., Raes D., Hermy M.. Landscape and Urban Planning, 77, 217-226 (2006).

35. DAFA. Dachy zielone. Wytyczne do Projektowania, Wykonywania i Pielegnacji Dachów ZielonychWytyczne dla Dachów Zielonych (Guidelines for Designing, Constructing and Caring for Green Roofs - Guidelines for Green Roofs) (in Polish); Stowarzyszenie Wykonawców Dachów Płaskich i Fasad (DAFA): Opole, Poland. (2015).

36. Szejba D., Szatyłowicz J., Gnatowski T. Przegląd Naukowy Inżynieria i Kształtowanie Środowiska, 26 (1), 66-74. (2017).

37. Voyde E., Fassman E., Simcock R.. Journal of Hydrology, 394, 384-395. (2010).

38. Getter K. L., Rowe D. B., Andresen J. Ecological Engineering, 31, 225-231. (2007).

39. Berretta C., Poë S., Stovin V. Journal of Hydrology, 511, 374-386. (2014).

40. Zhang Q., Miao L., Wang X., Liu D., Zhu L., Zhou B., Sun J., Liu J. Landsc. Urban Plan. 144, 142-150. (2015).

41. Hewelke E., Szatyłowicz J., Gnatowski T., Oleszczuk R. Rocz. Ochr. Środowiska, 16, 580-607. (2014).

42. Oleszczuk R., Gnatowski T., Brandyk T., Szatyłowicz J. Calibration of TDR for moisture content monitoring in moorsh layers. Wetlands: Monitoring, Modelling and Management. Taylor \& Francis, London, 121-124. (2007).

43. Wong G., Jim W. Ecological Engineering 85, 159172. (2015). 